\title{
Prognostic Factors in Patients Presenting with Pleural Effusion Revealing Malignancy
}

\author{
Stavros Anevlavis ${ }^{a} \quad$ George Kouliatsis $^{a}$ Ioannis Sotiriou ${ }^{a}$ \\ Michael I. Koukourakis ${ }^{b}$ Kostas Archontogeorgis ${ }^{a}$ Georgia Karpathiou ${ }^{c}$ \\ Alexandra Giatromanolakic Marios E. Froudarakis ${ }^{\mathrm{a}}$ \\ Departments of a Pneumonology, ${ }^{b}$ Radiation Oncology, and ${ }^{\mathrm{c} P a t h o l o g y, ~ M e d i c a l ~ S c h o o l ~ o f ~ A l e x a n d r o u p o l i s, ~}$ \\ Democritus University of Thrace, Alexandroupolis, Greece
}

\section{Key Words}

Thoracoscopy · Prognosis · Survival · Malignant pleural effusion · Factor

\begin{abstract}
Background: The survival of patients with malignant pleural effusion is considered generally poor. Most of the studies reporting results of prognostic factors are retrospective, using pleural thoracentesis for diagnosis. The objectives of our study were to reveal possible prognostic factors in patients initially presenting with undiagnosed pleural effusion proven to be malignant by diagnostic thoracoscopy. Methods: Ninety consecutive patients, 48 of whom were male (53\%), with a median age of 69 years (range 37-93) and a performance status (PS) of 0/1 (63\%) and with initially undiagnosed pleural effusion that was proven to be malignant by thoracoscopy were evaluated. Survival time was defined as the time from thoracoscopic diagnosis to death or the last follow-up. A regression analysis was used to determine significant clinical and biological prognostic factors. Results: Lung carcinoma (44.4\%), breast carcinoma (24.4\%), and mesothelioma (12.2\%) were the most frequent tumors diagnosed. The median overall survival was 11 months (range
\end{abstract}

$0.5-55)$. The survival of the patients was related to the following factors: histology of the primary tumor $(p=0.008)$, PS $(p<0.001)$, white blood cells $(p=0.018)$, and the blood neutrophil-to-lymphocyte $(N / L)$ ratio $(p=0.002)$. Multiple regression showed PS, histology, and the N/L ratio. Conclusion: The factors affecting survival in our patients were PS, primary tumor histology, and the N/L ratio. These factors may help physicians select patients for treatment and/or interventional procedures.

(c) 2014 S. Karger AG, Basel

\section{Introduction}

Malignant pleural effusion is a common medical problem in patients with cancer $[1,2]$. It usually occurs in patients with advanced neoplastic disease and it is associated with a reduced life expectancy $[3,4]$. Breast and lung cancers are responsible for approximately $75 \%$ of malig-

Part of this work was presented during the 19th European Respiratory Society Annual Congress in Vienna, Austria, in 2009 and at the 1 st European Congress of Interventional Pulmonology in Marseille, France, in 2011.

\section{KARGER}

E-Mail karger@karger.com www.karger.com/res
(C) 2014 S. Karger AG, Basel

0025-7931/14/0874-0311\$39.50/0
Marios E. Froudarakis, MD

Department of Pneumonology University Hospital of Alexandroupolis GR-68100 Alexandroupolis (Greece)

E-Mail mfroud@med.duth.gr 
nant pleural effusions [5]. Patients with malignant pleural effusion are considered to have a poor prognosis, with their quality of life affected by symptoms related to recurrent pleural effusion such as dyspnea, cough, and pain. In such patients, simple therapeutic thoracentesis might be the only option, while interventional procedures such as thoracoscopy with talc poudrage or chest tube insertion for blind pleurodesis are considered only in patients with a prolonged life expectancy $[1,6]$.

Several efforts have been made in the past to predict survival in patients with malignant pleural effusion. Most of the published reports have used clinical data [performance status (PS), cancer histology, and primary site] and biochemical parameters from pleural fluid examinations, such as $\mathrm{pH}$, lactate dehydrogenase (LDH), and glucose $[7-10]$. These investigations have also suggested that the extent of pleural lesions detected during thoracoscopy is closely related to both glucose and hydrogen ion concentrations in pleural fluid, and that the duration of survival is inversely related to the extent of carcinomatous involvement of the pleura $[10,11]$. Clinicians treating patients with malignant pleural effusion often rely on these increasingly controversial physiologic variables. In addition, they rely on their subjective assessment of the patient's potential for prolonged survival despite pleural involvement from the underlying malignancy.

Given the conflicting results regarding the prognostic value of pleural fluid $\mathrm{pH}$, glucose levels, and anatomic measures of the extent of pleural carcinomatosis, we performed a study of different variables potentially indicative of the prognosis of patients with malignant pleural effusion who underwent thoracoscopy for diagnostic purposes. The purpose of this prospective study was to determine the contribution of each of these variables to predicting survival in patients initially presenting with malignant pleural effusion who underwent thoracoscopy for diagnosis of their primary tumor (treatment-naive patients).

\section{Patients and Methods}

This is a prospective study of 90 patients with malignant pleural effusion out of 147 consecutive patients (61.2\%) who underwent diagnostic thoracoscopy from March 2006 to December 2011. All 90 patients had undergone thoracoscopy for diagnostic purpose as their pleural effusion was the initial condition of their underlying malignant disease; therefore, they were treatment-naive patients. The number of males was 48 (53.3\%). The median age was 69 years (range 37-93). Patients' characteristics are presented in table 1. Patients gave informed consent and the Internal Review Board of our hospital approved this study. All patients underwent single port of
Table 1. Characteristics of the study population $(n=90)$

\begin{tabular}{|c|c|}
\hline Characteristic & Value \\
\hline \multicolumn{2}{|l|}{ Gender, n (\%) } \\
\hline Males & $48(53.3)$ \\
\hline Females & $42(46.7)$ \\
\hline Median age (range), years & $69(37-93)$ \\
\hline \multicolumn{2}{|l|}{ Median pleural glucose level (range), } \\
\hline Median pleural pH (range) & $7.41(7.21-8.00)$ \\
\hline Median pleural LDH level (range), U/l & $587.5(120-2,058)$ \\
\hline \multicolumn{2}{|l|}{ PS, n (\%) } \\
\hline 0 & $39(43.3)$ \\
\hline 1 & $18(20)$ \\
\hline 2 & $25(27.7)$ \\
\hline 3 & $8(9)$ \\
\hline Median WBC (range), $\mathrm{n} / \mu \mathrm{l}$ & $8,450(4,200-18,800)$ \\
\hline Neutrophils & $5,700(2,570-16,620)$ \\
\hline Lymphocytes & $1,710(560-3,240)$ \\
\hline \multicolumn{2}{|l|}{ Diagnosis, n (\%) } \\
\hline NSCLC & $34(37.8)$ \\
\hline SCLC & $6(6.6)$ \\
\hline Breast cancer & $22(24.4)$ \\
\hline Mesothelioma & $11(12.2)$ \\
\hline Gastrointestinal cancer & $4(4.4)$ \\
\hline Head-neck cancer & $3(3.3)$ \\
\hline Ovarian cancer & $3(3.3)$ \\
\hline Genitourinary cancer & $2(2.2)$ \\
\hline Lymphoma & $2(2.2)$ \\
\hline Unknown & $3(3.3)$ \\
\hline \multicolumn{2}{|l|}{ Type of intervention, $\mathrm{n}(\%)$} \\
\hline Diagnostic thoracoscopy & $52(57.8)$ \\
\hline Talc pleurodesis & $38(42.2)$ \\
\hline \multicolumn{2}{|l|}{ Mean pleural drainage time } \\
\hline (range), days & $3(1-7)$ \\
\hline \multicolumn{2}{|l|}{ Side of thoracoscopy, $\mathrm{n}(\%)$} \\
\hline Left & $49(54.4)$ \\
\hline Right & $41(45.6)$ \\
\hline
\end{tabular}

entry thoracoscopy under local anesthesia, with spontaneous ventilation, in the endoscopy suite $[6,12]$.

Pleurodesis was performed during a second thoracoscopy by insufflating $4 \mathrm{~g}$ sterile asbestos-free talc (Steritalc ${ }^{\circledR}$; Novatech, France) into the patients' pleural space only after histological confirmation (on-site evaluation is not available in our settings) of metastatic disease, after a full case-by-case evaluation and discussion of the possible benefits according to the origin of the primary tumor and the efficacy of the therapy. The chest tube (20-french gauge) was removed after lung reexpansion in the case of diagnostic procedures, while in the case of pleurodesis it was removed when less than $100 \mathrm{ml}$ pleural fluid was drained over a 24-hour period $[6,12]$.

Survival was studied in relation to other clinical parameters such as gender, the histology of the primary tumor, PS according to the ECOG score, and the type of intervention (talc pleurodesis vs. diagnostic thoracoscopy), as well as in relation to biological pa- 


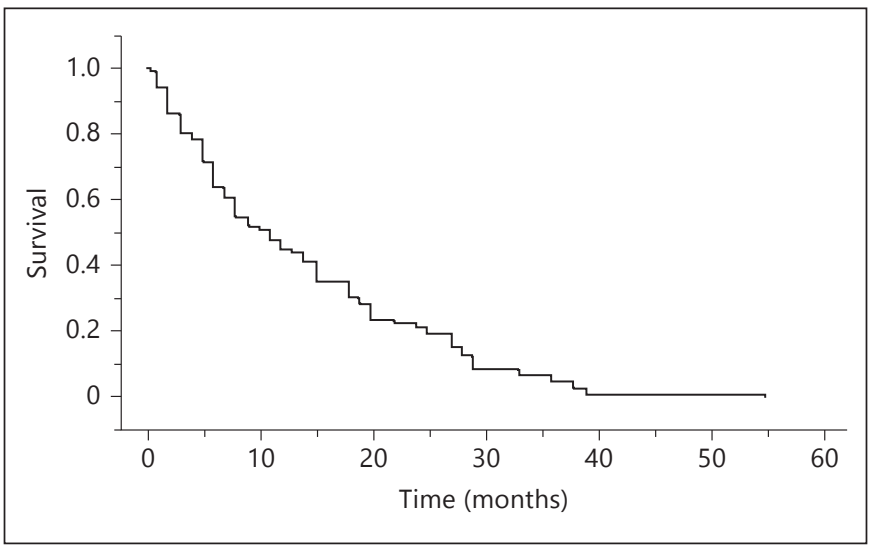

Fig. 1. Overall survival of our patients $(n=90)$.

rameters such as peripheral blood white cells (WBC), neutrophils, lymphocytes, the neutrophil-to-lymphocyte (N/L) ratio, pleural fluid $\mathrm{pH}, \mathrm{LDH}$, and glucose. Survival was measured from the time of diagnostic thoracoscopy to the date of death or the last follow up. This study was conducted in such a way that living patients could have at least a 3-year follow-up. All biological tests were carried out 1 day prior to the intervention.

\section{Statistical Analysis}

The Kaplan-Meier method was employed to determine the relationships between patient survival and other potential clinical or biological parameters such as gender, histology of the primary tumor, side of thoracoscopy, and mode of intervention (diagnostic vs. talc poudrage). A univariate analysis was performed to analyze the prognostic contribution of continuous variables such as age and blood and pleural fluid parameters. A Cox proportional hazards model was used to assess the independent prognostic value of each covariate selected by the univariate regression analysis [4]. $\mathrm{p}<0.05$ was considered statistically significant. All analyses were performed using StatView ${ }^{\mathrm{TM}} 4.5$ statistical software (Abacus Concepts Inc., Berkeley, Calif., USA).

\section{Results}

Our patients' overall median survival was 11 months (range 0.5-55) (fig. 1). The Kaplan-Meier analysis showed that survival was significantly related $(\mathrm{p}<0.001)$ to ECOG PS (fig. 2a). Patients with ECOG PS 0 had the best median survival (24 months), while patients with a score of 1,2 , or 3 had a median survival of 9,5 , or 1.5 months, respectively. Survival was also significantly related $(\mathrm{p}=$ 0.008 ) to the type of primary tumor (table 2). Patients with lymphoma had the best median survival (26 months), and patients with ovary and breast carcinomas had the second best survival (18 and 15 months, respectively) (table 2). Patients with non-small cell lung cancer (NSCLC) and small cell lung cancer (SCLC) had a survival time of 9.5 and 6 months, respectively, while mesothelioma patients had an 8-month survival time (table 2). Other parameters examined, such as gender $(\mathrm{p}=0.33)$, age $>70$ years ( $\mathrm{p}=0.2$ ), type of intervention (diagnostic thoracoscopy vs. talc poudrage) $(\mathrm{p}=0.14)$, and side of thoracoscopy $(p=0.62)$, did not affect survival. However, there was a trend towards better survival in patients who underwent thoracoscopic talc pleurodesis (median $=14$ months) compared to those without pleurodesis (median $=8.5$ months) (fig. 2b).

Univariate analysis (table 3 ) showed poor survival with increasing WBC $\left(\mathrm{p}=0.0016, \mathrm{r}^{2}=0.058\right)$, increasing blood neutrophils $\left(\mathrm{p}=0.018, \mathrm{r}^{2}=0.055\right)$, decreasing blood lymphocytes ( $\left.\mathrm{p}=0.015, \mathrm{r}^{2}=0.14\right)$, and increasing blood N/L ratios $\left(\mathrm{p}=0.0093, \mathrm{r}^{2}=0.066\right)$. Patients with $\mathrm{WBC}<13,000 / \mathrm{mm}^{3}$ (fig. $2 \mathrm{c}$ ) and those with $\mathrm{N} / \mathrm{L}$ ratios $<3$ (fig. $2 \mathrm{~d})$ showed significantly better survival $(\mathrm{p}=0.001$ and $p=0.002$, respectively). The simple regression analysis was unable to show any significant relationship between survival and pleural fluid $\mathrm{pH}$, glucose, proteins, and $\mathrm{LDH}$ (table 3 ). When we stratified our patients by primary tumor in order to study the relation between pleural $\mathrm{pH}$ and survival, we were unable to reveal any impact of pleural $\mathrm{pH}$ (mesotheliomas: $\mathrm{R}^{2}=0.17, \mathrm{p}=0.64$; metastatic carcinomas: $\mathrm{R}^{2}=0.16, \mathrm{p}=0.37$, and lung carcinomas: $\mathrm{R}^{2}=0.15, \mathrm{p}=0.54$ ).

Cox proportional hazards analysis showed that ECOG PS, histology of the primary tumor, and N/L ratio were independent factors affecting patient survival $(\mathrm{p}=0.020$, $p=0.022$ and $p=0.03$, respectively).

\section{Discussion}

This study was designed to evaluate potential prognostic variables in patients presenting with initially undiagnosed pleural effusion diagnosed as malignant after diagnostic thoracoscopy. We found that the primary tumor, the ECOG PS, WBC, and the N/L ratio were predictors of survival in this patient population. No pleural fluid parameter tested showed any association with survival in our patient population.

PS is an indisputable prognostic factor in cancer patients. Indeed, our results are consistent with other reports which found that PS was a significant predictor variable in patients with recurrent symptomatic malignant effusions undergoing thoracoscopic pleurodesis [4, 13]. Despite the presence of a pleural effusion, there is a strong correlation between the performance scale score 


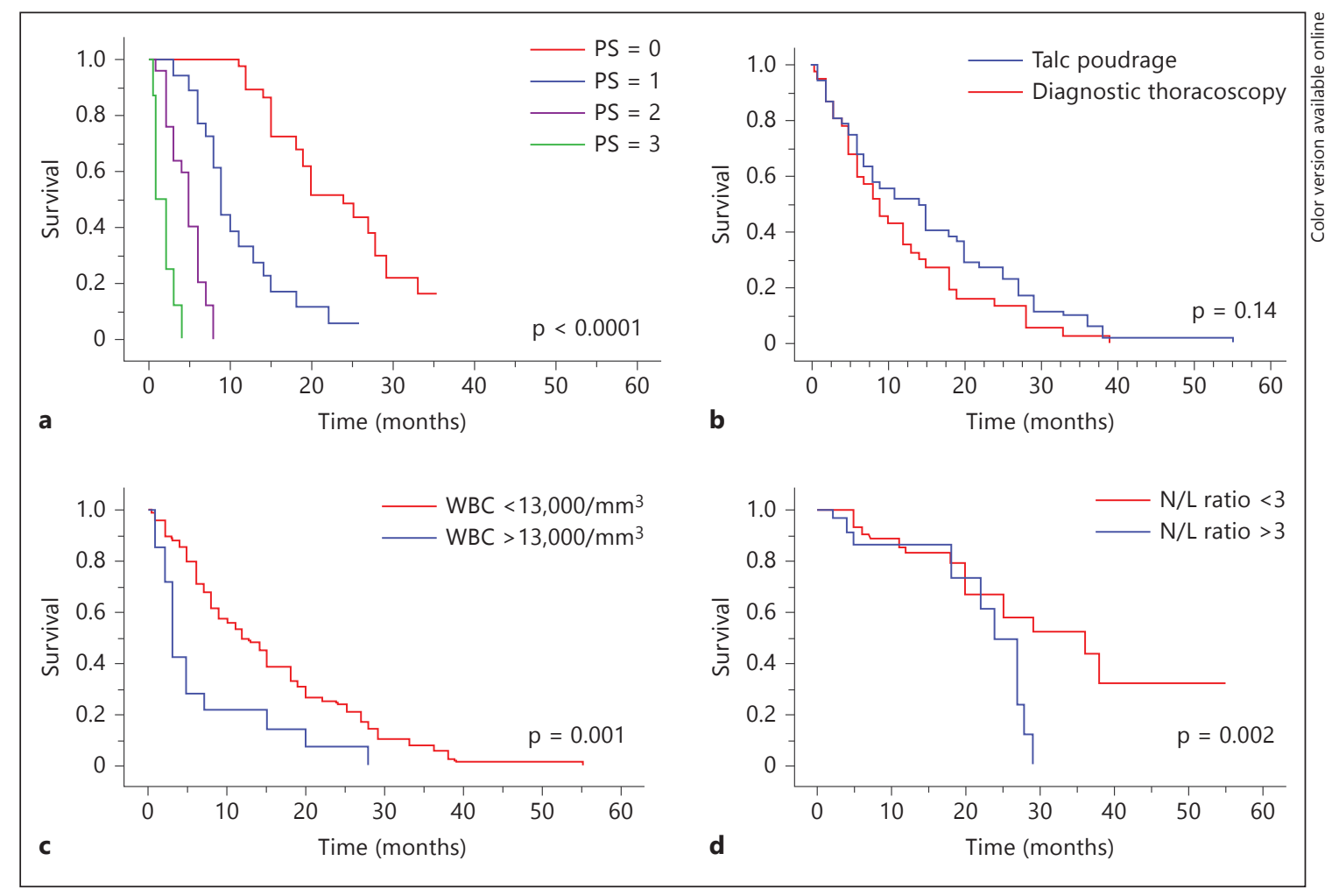

Fig. 2. Patient survival according to the studied parameters: ECOG PS (a), mode of intervention (diagnostic thoracoscopy vs. talc poudrage) (b), WBC (c), and the N/L ratio (d).

Table 2. Survival according to primary tumor (overall $\mathrm{p}=0.008$ )

\begin{tabular}{lc}
\hline Type of malignancy & Median survival (range), months \\
\hline Lymphoma & $26(24-28)$ \\
Ovary & $18(3-20)$ \\
Breast & $15(2-33)$ \\
Gastrointestinal & $13.5(1-27)$ \\
Head-neck & $12(12-13)$ \\
Genitourinary & $11.5(8-15)$ \\
NSCLC & $9.5(1-39)$ \\
Mesothelioma & $8(2-55)$ \\
SCLC & $6(2-9)$ \\
Unknown & $1(0.5-7)$ \\
Overall & $11(0.5-55)$ \\
\hline
\end{tabular}

and the survival of patients with lung cancer, lymphoma, and solid tumors [14-16].

In our study, the histology of the primary tumor was an independent prognostic factor. In all of our study patients, the primary tumor was diagnosed via thoracoscopic biopsy after referral for an undiagnosed pleural effusion. As shown in table 1, our patients presented
Table 3. Simple regression analysis for age, blood, and pleural fluid variables in relation to survival $(n=90)$

\begin{tabular}{llccl}
\hline Parameter & $\mathrm{R}^{2}$ & $\mathrm{SE}$ & $\mathrm{t}$ value & $\mathrm{p}$ value \\
\hline Age & 0.032 & 0.106 & -1.7 & 0.09 \\
WBC & 0.072 & 0.003 & -2.5 & 0.012 \\
Blood neutrophils & 0.064 & 0.004 & -2.44 & 0.016 \\
Blood lymphocytes & 0.14 & 0.003 & 2.54 & 0.015 \\
Blood N/L ratio & 0.063 & 0.48 & -2.4 & 0.017 \\
Pleural pH & 0.047 & 11.6 & -1.5 & 0.13 \\
Pleural glucose & 0.001 & 0.37 & -0.16 & 0.87 \\
Pleural proteins & 0.032 & 1.7 & 1.6 & 0.11 \\
Pleural LDH & 0.002 & 0.003 & 0.33 & 0.73 \\
\hline
\end{tabular}

overall with a good PS [PS 0/1, $\mathrm{n}=57$ (63.3\%); PS 2/3, $\mathrm{n}=33(37.7 \%)]$. Also, as the patients in our series were primarily diagnosed by thoracoscopy, they were treatment naive and therefore more likely to do better, especially those with chemosensitive tumors such as breast and ovary tumors, carcinomas, and lymphomas. Although generally the occurrence of pleural effusion is 
believed to be indicative of a poor prognosis in cancer patients $[1,3,4]$, it is logical to consider differences depending on the primary tumor $[10,17]$ as the overall survival and time to progression vary according to the behavior of each tumor in response to treatment. Indeed, most published series include patients with a pleural effusion presenting when the disease has progressed, relapsed, and/or is resistant to any treatment $[4,13]$; that is not the case in our series, which includes only patients whose disease was diagnosed through the occurrence of pleural effusion.

Increased WBC and blood neutrophils, decreased lymphocytes, and an increased N/L ratio were statistically significantly correlated with poor survival in our univariate analysis. Only the N/L ratio was an independent factor predicting survival. Increased WBC with an increased neutrophil count have been identified as an independent predictor of death in patients with advanced NSCLC $[18,19]$. A high neutrophil count has been reported as an adverse marker of prognosis in metastatic melanoma [20] and renal cell carcinoma [21], while a low lymphocyte count has been reported as a marker of mortality in pancreatic and breast cancer [22]. The causes of lymphopenia in cancer patients may vary. It may result in part from the destruction of lymphocytes by the tumor, and/or from impaired differentiation of lymphocyte progenitors [23]. Peripheral blood lymphopenia is a recognized predictor of poor survival in patients with advanced cancer, attributed to the fundamental role of lymphocytes in cell-mediated immunity with the destruction of host cancer cells [24]. An increased N/L ratio is an important indicator of an adverse prognosis in colorectal $[25,26]$ and gastric [27] cancers as in the case of our patients. Interestingly, in early-stage NSCLC an increased preoperative N/L ratio is an independent predictor of poor survival after complete resection of the tumor, and it is a potential biomarker to stratify patients with stage I disease with a high risk of death [28].

Thoracoscopic talc poudrage is the local treatment of choice in this patient population. The earlier it is performed, the better the results we expect are, with maintenance of the patient's PS and quality of life $[29,30]$. Talc pleurodesis was not a factor for better survival in our patients with malignant pleural effusion. Talc has been implicated in patients with prolonged survival after pleurodesis. Recent studies showed that talc may act directly on cancer cells by inducing apoptosis or it may inhibit neoangiogenesis [31]. Since our patient population was newly diagnosed (treatment-naive patients), this finding might be due to the fact that survival may be re- lated to treatment response as has also been reported in other studies [3, 4].

We found no statistically significant correlation of survival with pleural fluid $\mathrm{pH}$, glucose, $\mathrm{LDH}$, or the number of pleural fluid WBC. Controversy exists regarding whether pleural biological parameters are associated with survival in patients with malignant pleural effusion; some authors believe that low pleural $\mathrm{pH}$ and glucose levels are related to poor survival $[8,9]$, while others believe these values do not help predict patient outcomes [4, 32, 33]. The selection of patients with old and/or already known pleural effusions may explain these findings as the older the effusion is, the lower the pleural $\mathrm{pH}$ and glucose levels are. These patients have probably already consumed their survival at the time of evaluation by presenting a tumor relapse or resistance to chemotherapy. Another issue is differences in survival according to the pleural $\mathrm{pH}$ of patients with mesothelioma compared to other primaries [17]. We were unable to show any relation between pleural $\mathrm{pH}$ and survival after stratification of our patients by primary tumor. A possible explanation for this discrepancy is that we had confirmed diagnoses of mesothelioma by thoracoscopic biopsy, while others had diagnosis conformation by simple thoracentesis [17]. In agreement with our findings, a meta-analysis clearly showed that there is no relation between pleural $\mathrm{pH}$ and the survival of patients with malignant pleural effusions [34].

Gender was not a prognostic factor in our study. Indeed, despite our 25 female patients with breast and ovary carcinoma, of the remaining 17 female patients, 10 patients presented with NSCLC and 3 patients had mesothelioma. Patients with NSCLC presenting with metastatic pleural effusion have a poor median survival of 8.5 months [35], and they have been reclassified lately by the IASLC as having stage M1a disease [36]. Mesothelioma is also a highly aggressive tumor with a poor median survival [37].

In our study, histology of the primary tumor, ECOG PS, and the blood N/L ratio were found to be predictors of survival in patients with malignant pleural effusion as the initial manifestation necessitating thoracoscopy to reveal the primary tumor. These factors may help physicians select patients for treatment and/or interventional procedures.

\section{Financial Disclosure and Conflicts of Interest}

The authors have no conflicts to disclose. 


\section{References}

1 Froudarakis ME: Diagnostic work-up of pleural effusions. Respiration 2008;75:4-13.

$\checkmark 2$ Froudarakis ME: Pleural diseases in the molecular era: time for more answers - introduction. Respiration 2012;83:2-4.

$\checkmark 3$ Chernow B, Sahn SA: Carcinomatous involvement of the pleura: an analysis of $96 \mathrm{pa}-$ tients. Am J Med 1977;63:695-702.

4 Burrows CM, Mathews WC, Colt HG: Predicting survival in patients with recurrent symptomatic malignant pleural effusions: an assessment of the prognostic values of physiologic, morphologic, and quality of life measures of extent of disease. Chest 2000;117:73-78.

5 Zimmer PW, Hill M, Casey K, Harvey E, Low DE: Prospective randomized trial of talc slurry vs. bleomycin in pleurodesis for symptomatic malignant pleural effusions. Chest 1997; 112:430-434.

6 Rodriguez-Panadero F, Janssen JP, Astoul P: Thoracoscopy: general overview and place in the diagnosis and management of pleural effusion. Eur Respir J 2006;28:409-422.

7 Good JT Jr, Taryle DA, Sahn SA: The pathogenesis of low glucose, low $\mathrm{pH}$ malignant effusions. Am Rev Respir Dis 1985;131:737741.

8 Sahn SA, Good JT Jr: Pleural fluid pH in malignant effusions: diagnostic, prognostic, and therapeutic implications. Ann Intern Med 1988;108:345-349.

-9 Rodriguez-Panadero F, Lopez Mejias J: Low glucose and $\mathrm{pH}$ levels in malignant pleural effusions: diagnostic significance and prognostic value in respect to pleurodesis. Am Rev Respir Dis 1989;139:663-667.

$\checkmark 10$ Sanchez-Armengol A, Rodriguez-Panadero F: Survival and talc pleurodesis in metastatic pleural carcinoma, revisited: report of 125 cases. Chest 1993;104:1482-1485.

11 Rodriguez-Panadero F, Lopez-Mejias J: Survival time of patients with pleural metastatic carcinoma predicted by glucose and $\mathrm{pH}$ studies. Chest 1989;95:320-324.

12 Froudarakis ME, Klimathianaki M, Pougounias M: Systemic inflammatory reaction after thoracoscopic talc poudrage. Chest 2006;129: 356-361.

-13 Steger V, Mika U, Toomes H, Walker T, Engel C, Kyriss T, Ziemer G, Friedel G: Who gains most? A 10-year experience with 611 thoracoscopic talc pleurodeses. Ann Thorac Surg 2007;83:1940-1945.

14 Buccheri G, Ferrigno D, Vola F: Carcinoembryonic antigen (CEA), tissue polypeptide antigen (TPA) and other prognostic indicators in squamous cell lung cancer. Lung Cancer 1993;10:21-33.
15 Martinez-Moragon E, Aparicio J, Sanchis J, Menendez R, Cruz Rogado M, Sanchis F: Malignant pleural effusion: prognostic factors for survival and response to chemical pleurodesis in a series of 120 cases. Respiration 1998;65: 108-113.

16 Stanley KE: Prognostic factors for survival in patients with inoperable lung cancer. J Natl Cancer Inst 1980;65:25-32.

17 Bielsa S, Salud A, Martinez M, Esquerda A, Martin A, Rodriguez-Panadero F, Porcel JM: Prognostic significance of pleural fluid data in patients with malignant effusion. Eur J Intern Med 2008; 19:334-339.

18 Sculier JP, Chansky K, Crowley JJ, Van Meerbeeck J, Goldstraw P: The impact of additional prognostic factors on survival and their relationship with the anatomical extent of disease expressed by the 6th edition of the TNM classification of malignant tumors and the proposals for the 7 th edition. J Thorac Oncol 2008;3:457-466.

19 Paesmans M, Sculier JP, Libert P, Bureau G, Dabouis G, Thiriaux J, Michel J, Van Cutsem O, Sergysels R, Mommen P, et al: Prognostic factors for survival in advanced non-smallcell lung cancer: univariate and multivariate analyses including recursive partitioning and amalgamation algorithms in 1,052 patients the European Lung Cancer Working Party. J Clin Oncol 1995;13:1221-1230.

20 Schmidt H, Bastholt L, Geertsen P, Christensen IJ, Larsen S, Gehl J, von der Maase H: Elevated neutrophil and monocyte counts in peripheral blood are associated with poor survival in patients with metastatic melanoma: a prognostic model. Br J Cancer 2005;93:273278.

21 Atzpodien J, Royston P, Wandert T, Reitz M: Metastatic renal carcinoma comprehensive prognostic system. Br J Cancer 2003;88:348353.

22 Fogar P, Sperti C, Basso D, Sanzari MC, Greco E, Davoli C, Navaglia F, Zambon CF, Pasquali C, Venza E, Pedrazzoli S, Plebani M: Decreased total lymphocyte counts in pancreatic cancer: an index of adverse outcome. Pancreas 2006;32:22-28.

23 Adzic TN, Pesut DP, Nagorni-Obradovic LM, Stojsic JM, Vasiljevic MD, Bouros D: Clinical features of lung cancer in patients with connective tissue diseases: a 10-year hospital based study. Respir Med 2008;102:620-624.

24 Lissoni P, Brivio F, Fumagalli L, Messina G, Ghezzi V, Frontini L, Giani L, Vaghi M, Ardizzoia A, Gardani GS: Efficacy of cancer chemotherapy in relation to the pretreatment number of lymphocytes in patients with metastatic solid tumors. Int J Biol Markers 2004; 19:135-140.
25 Walsh SR, Cook EJ, Goulder F, Justin TA, Keeling NJ: Neutrophil-lymphocyte ratio as a prognostic factor in colorectal cancer. J Surg Oncol 2005;91:181-184.

-26 Halazun KJ, Aldoori A, Malik HZ, AlMukhtar A, Prasad KR, Toogood GJ, Lodge JP: Elevated preoperative neutrophil to lymphocyte ratio predicts survival following hepatic resection for colorectal liver metastases. Eur J Surg Oncol 2008;34:55-60.

27 Hirashima M, Higuchi S, Sakamoto K, Nishiyama $\mathrm{T}$, Okada $\mathrm{H}$ : The ratio of neutrophils to lymphocytes and the phenotypes of neutrophils in patients with early gastric cancer. J Cancer Res Clin Oncol 1998;124:329-334.

28 Sarraf KM, Belcher E, Raevsky E, Nicholson AG, Goldstraw P, Lim E: Neutrophil/lymphocyte ratio and its association with survival after complete resection in non-small cell lung cancer. J Thorac Cardiovasc Surg 2009;137: 425-428.

29 Bouros D, Froudarakis M, Siafakas NM: Pleurodesis: everything flows. Chest 2000; 118:577-579.

30 Rodriguez-Panadero F: Medical thoracoscopy. Respiration 2008;76:363-372.

31 Rodriguez-Panadero F, Montes-Worboys A: Mechanisms of pleurodesis. Respiration 2012;83:91-98

32 Bilaceroglu S, Cagirici U, Perim K, Ozacar R: Corynebacterium parvum pleurodesis and survival is not significantly influenced by pleural $\mathrm{pH}$ and glucose level. Monaldi Arch Chest Dis 1998;53:14-22.

33 Foresti V, Scolari N, Villa A, Parisio E, De Filippi G, Guareschi G: Malignant pleural effusions: meaning of pleural-fluid $\mathrm{pH}$ determination. Oncology 1990;47:62-64.

34 Heffner JE, Nietert PJ, Barbieri C: Pleural fluid $\mathrm{pH}$ as a predictor of survival for patients with malignant pleural effusions. Chest 2000; 117:79-86

35 Froudarakis ME: Pleural effusion in lung cancer: more questions than answers. Respiration 2012;83:367-376.

36 Goldstraw P, Crowley J, Chansky K, Giroux DJ, Groome PA, Rami-Porta R, Postmus PE, Rusch V, Sobin L: The IASLC lung cancer staging project: proposals for the revision of the TNM stage groupings in the forthcoming (seventh) edition of the TNM classification of malignant tumours. J Thorac Oncol 2007;2: 706-714.

37 Astoul P, Roca E, Galateau-Salle F, Scherpereel A: Malignant pleural mesothelioma: from the bench to the bedside. Respiration 2012;83: 481-493. 